\title{
Relationship Between the Skin Surface Temperature Changes During Sprint Interval Testing Protocol and the Aerobic Capacity in Well- Trained Cyclists
}

\author{
R. HEBISZ ${ }^{1}$, P. HEBISZ ${ }^{1}$, J. BORKOWSKI ${ }^{1}$, I. WIERZBICKA-DAMSKA ${ }^{1}$, M. ZATOŃ ${ }^{1}$ \\ ${ }^{1}$ Department of Physiology and Biochemistry, University School of Physical Education in \\ Wroclaw, Poland
}

Received January 7, 2019

Accepted June 20, 2019

Epub Ahead of Print October 25, 2019

\begin{abstract}
Summary
The study investigated whether changes in body surface temperature in a sprint interval testing protocol (SITP) correlated with aerobic capacity in cyclists. The study involved 21 welltrained cyclists. Maximal aerobic power and maximal oxygen uptake relative to lean body mass $\left(\mathrm{LBM}-\mathrm{P}_{\max }\right.$ and $\mathrm{LBM}-\mathrm{VO}_{2 \max }$ respectively) were determined by incremental exercise testing on a cycle ergometer. SITP was administered 48 hours later and involved four 30-s maximal sprints interspersed with 90 -s active recovery. Body surface temperature was recorded at the temple and arm and the delta difference between baseline temperature and temperature measured immediately after the first sprint $\left(\Delta \mathrm{Tt}_{1}\right.$ and $\Delta \mathrm{Ta}_{1}$, respectively) and 80 seconds after the fourth sprint ( $\Delta \mathrm{Tt}_{4}$ and $\Delta \mathrm{Ta}_{4}$, respectively) was calculated. Significant correlations were found between $\Delta \mathrm{Tt}_{4}$ and $L B M-\mathrm{P}_{\max }$ and

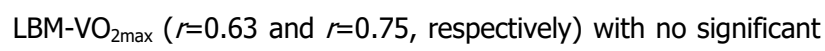
change in $\Delta \mathrm{Ta}_{1}$ or $\Delta \mathrm{Ta}_{4}$. Body surface temperature, measured at the temple region, can be used to indirectly assess aerobic capacity during maximal sprint exercise.
\end{abstract}

\section{Key words}

Body surface temperature • Thermoregulation • Maximal oxygen uptake • Maximal sprint exercise

\section{Corresponding author}

Paulina Hebisz, University School of Physical Education, Department of Physiology and Biochemistry, 35 J.I. Paderewski Avenue, 51-612 Wroclaw, Poland. E-mail: paulinahebisz@interia.pl

\section{Introduction}

Maximal oxygen uptake $\left(\mathrm{VO}_{2 \max }\right)$ is one of several physiological factors determining the endurance performance in athletes. (Levine 2008, Lucia et al. 2001, Mujika and Padilla 2001a). $\mathrm{VO}_{2 \max }$ is also important in efforts that involve single and repeated sprints due to its relationship with the rate of phosphocreatine resynthesis, phosphate concentration, and energy production via aerobic glycolysis (Girard et al. 2011, Glaister 2005). $\mathrm{VO}_{2 \max }$ is treated as a reliable and valid measure of training-induced changes in exercise capacity (Coquart et al. 2014) and has been used as a criterion in the athlete selection process (Faria et al. 2005). Among non-athletes, $\mathrm{VO}_{2 \max }$ has been reported to reflect the efficiency of the cardiovascular (De Lorenzo et al. 2018) and respiratory system (Lopes et al. 2018) or muscular content of energy metabolism proteins (Vigelsø et al. 2016).

Another important indicator of performance among endurance athletes is the body's thermoregulatory response to exercise, which ensures that the core temperature is maintained within a temperature range which will conserve the physiological functions (Nybo and Nielsen 2001). There exists an inter-relationship between $\mathrm{VO}_{2 \max }$ and exercise-induced changes in internal temperature, in which temperature is dependent on relative exercise load, which can be expressed as a percentage of individual $\mathrm{VO}_{2 \max }$ (Yoshida et al. 1997). Hence, individuals with different levels of aerobic capacity show a similar increase in temperature during exercise at a similar relative load despite significant 
variation in power output. The body's thermoregulatory response to exercise is thought to be dependent, among several other factors, on the distribution of blood and several hemodynamic mechanisms. At the onset of dynamic exercise of large muscle groups, the body signals a vasoconstrictor response in non-exercising muscle (Johnson 1992, Kamon and Belding 1969, Simmons et al. 2011). This reduction in blood flow is greatest during maximal-intensity exercise (Taylor et al. 1990). Concomitantly, blood flow to working skeletal muscle is enhanced by vasodilatation in order to meet the metabolic demands of contracting muscles (Kenney and Johnson 1992). Previous research has found cutaneous blood flow to be significantly higher in trained subjects compared with untrained cohorts (Fritzsche and Coyle 2000; Johnson 1998). The changes in blood flow and distribution are easily observable by the decrease in body surface temperature in the first minutes of exercise (Kamon and Belding 1969, Simmons et al. 2011) followed by an increase in the body surface temperature with continued exercise (Kamon and Belding 1969, Simmons et al. 2011) as cutaneous blood flow increases (Johnson and Rowell 1975). The onset of perspiration and further temperature modulation is then dependent on several internal (aerobic capacity and cutaneous blood circulation) and external (ambient temperature and other environmental conditions) factors (Tankersley et al. 1991, Wingo et al. 2010).

The efficacy of the body's thermoregulatory mechanisms for eliminating excess heat, particularly those which protect brain tissue from overheating, is an important determinant of exercise performance. Body temperature among endurance athletes can reach $41.5^{\circ} \mathrm{C}$ during intense exercise (Racinais et al. 2019). For this reason, the inclusion of a heat acclimatization component in athlete training has been suggested in order to improve work output and increase $\mathrm{VO}_{2 \max }$ (Lorenzo et al. 2010). These physiological adaptations are explained by an increase in plasma volume and have been observed after a heat acclimation program (Lorenzo et al. 2010) or after interval (Abderrahman et al. 2013) or endurance training (Martino et al. 2002, Warburton et al. 2004). The exercise-induced expansion in plasma volume is considered by many to be beneficial as it can also enhance performance during heavy exercise by facilitating thermoregulation (Coles and Luetkemeier 2005, Nelson et al. 2008) or reducing blood viscosity (Abderrahman et al. 2013).

The above cited works suggest a relationship between thermoregulatory efficacy, $\mathrm{VO}_{2 \max }$, and exercise performance. However, little is known about the effects of maximal exercise on changes in body surface temperature among athletes with high levels of $\mathrm{VO}_{2} \max$ and maximal aerobic power. A correlation between aerobic capacity and exercise-induced changes in body surface temperature could provide a regular estimate of $\mathrm{VO}_{2 \max }$ during the training cycle. The aim of this study was to investigate this association in well-trained cyclists during a single sprint interval training session. It was assumed that the high maximal oxygen uptake allows more efficient blood flow through the cutaneous vessels, influencing the elimination of increasing temperature during sprint interval testing protocol.

\section{Methods}

\section{Participants}

Twenty-one well-trained mountain bike (MTB) cyclists aged 17-22 years participated in the study. All had been regularly training MTB for at least 3 years. Table 1 presents the basic anthropometric and the aerobic capacity characteristics of the cyclists. The study was approved by a local ethics committee and all procedures were designed to be in accordance with the Declaration of Helsinki. The participants were familiarized with the research protocol and provided their written consent to participate in the study.

Table 1. Anthropometric and physiological characteristics of the studied group.

\begin{tabular}{cccccccc}
\hline $\begin{array}{c}\text { Age } \\
\text { [years] }\end{array}$ & $\begin{array}{c}\text { Mass } \\
{[\mathbf{k g}]}\end{array}$ & $\begin{array}{c}\text { Height } \\
{[\mathbf{c m}]}\end{array}$ & $\begin{array}{c}\text { Fat tissue } \\
{[\mathbf{\%}]}\end{array}$ & $\begin{array}{c}\mathbf{L B M} \\
{[\mathbf{k g}]}\end{array}$ & $\begin{array}{c}\mathbf{V O}_{2 \max } \\
{\left[\mathbf{m} \cdot \mathbf{m i n}^{-1} \cdot \mathbf{k g}^{-\mathbf{1}}\right]}\end{array}$ & $\begin{array}{c}\mathbf{P}_{\text {max }} \\
{\left[\mathbf{W} \cdot \mathbf{k g}^{-1}\right]}\end{array}$ & $\begin{array}{c}\mathbf{T}_{\text {plateau }} \\
{[\mathbf{s}]}\end{array}$ \\
\hline 18.9 & 67.3 & 178.1 & 13.2 & 58.3 & 66.3 & 5.6 & 117.6 \\
$(2.2)$ & $(6.6)$ & $(5.6)$ & $(4.1)$ & $(7.3)$ & $(4.6)$ & $(0.3)$ & $(51.8)$ \\
\hline
\end{tabular}

LBM - lean body mass, $\mathrm{VO}_{2 \max }$ - maximal oxygen uptake; $\mathrm{P}_{\max }$ - maximal aerobic power; $\mathrm{T}_{\text {plateau }}$ - time of plateau $\mathrm{VO}_{2}$ max; data are presented as arithmetic mean (standard deviation). 


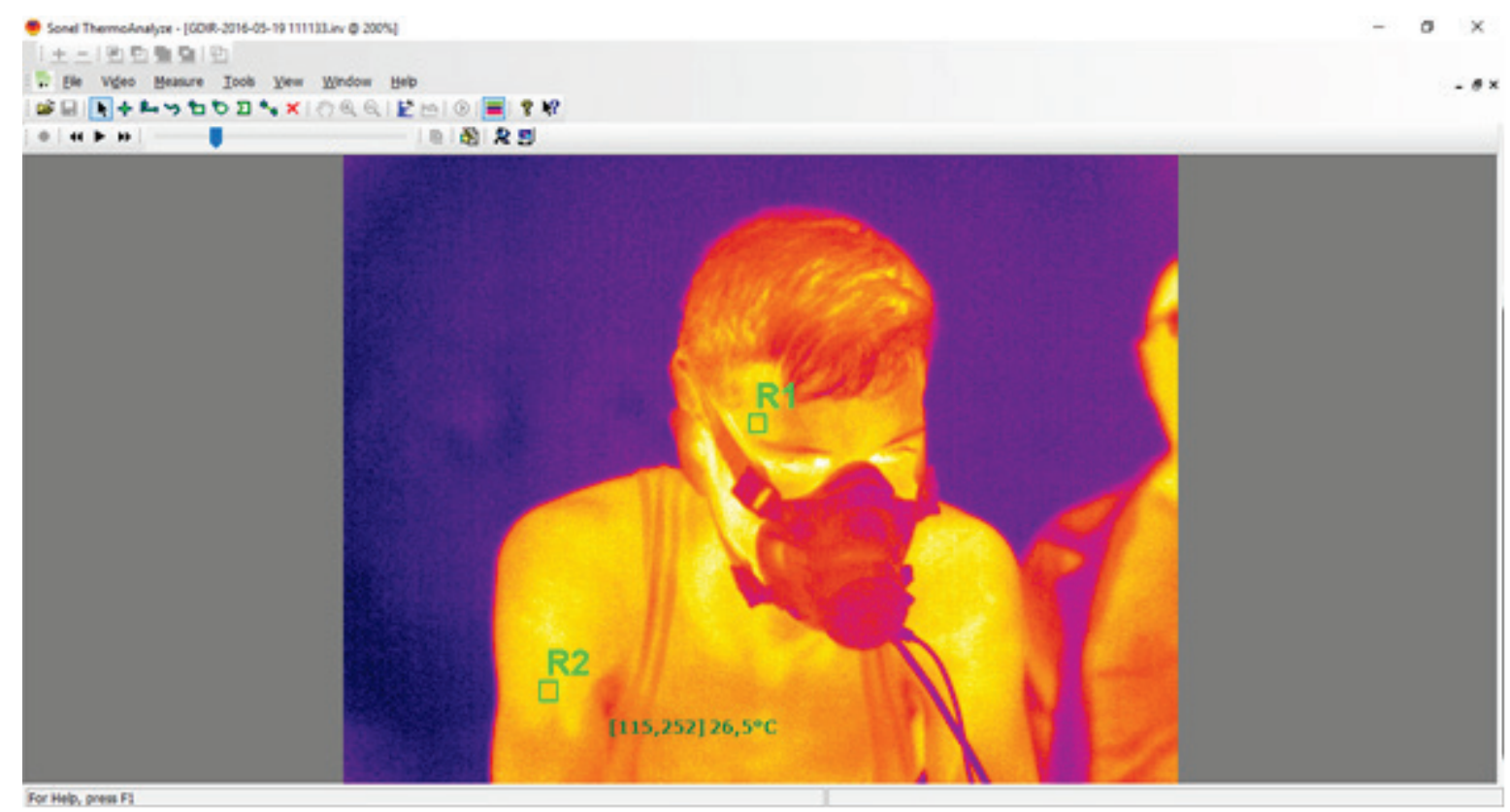

Fig. 1. A single frame of a film recorded during SITP with marked fields for the temple surface temperature (R1) and arm surface temperature (R2) analysis.

\section{Experimental design}

The participants were instructed to refrain from any physical exercise 48 hours prior to the experiment. First the participants performed an incremental testing protocol (ITP) to determine aerobic capacity and then $48 \mathrm{~h}$ later a sprint interval testing protocol (SITP). Testing was performed in controlled laboratory conditions (ambient temperature $20.5{ }^{\circ} \mathrm{C}$ at $55-60 \%$ humidity) in the Exercise Laboratory of the University School of Physical Education (PN-EN ISO 9001:2001 certified).

\section{Incremental testing protocol}

Body composition was determined by ultrasound prior to testing using a Bodymetrix analyzer (Intelametrix, Brentwood, USA). Body mass (BM) was recorded in $\mathrm{kg}$ and body fat percentage (BF \%) was determined at nine measurements sites (biceps, triceps, chest, scapula, lower back, waist, hip, thigh, and calf). Lean body mass (LBM) in $\mathrm{kg}$ was then calculated using the formula $\mathrm{LBM}=\mathrm{BM}-(\mathrm{BM}-\% \mathrm{BF})$. The ITP was performed on a Lode Excalibur Sport cycle ergometer (Lode B.V. Groningen, Netherlands) calibrated before each trial. Starting workload was set at $50 \mathrm{~W}$ and increased by $50 \mathrm{~W}$ every $3 \mathrm{~min}$ until volitional exhaustion was reached. If the participant was unable to complete an entire 3 min stage, $0.28 \mathrm{~W}$ was subtracted for each missing second from the work rate at that stage. The highest power output determined in the ITP was recorded as maximal aerobic power $\left(\mathrm{P}_{\max }\right)$.
Respiratory function was measured throughout the test by a Quark gas analyzer (Cosmed, Milan, Italy). The gas analyzer was calibrated before each trial with a reference gas mixture of carbon dioxide (5\%), oxygen $(16 \%)$, and nitrogen $(79 \%)$. The participant wore a face mask and tidal air was analyzed on a breath-by-breath basis to determine oxygen uptake $\left(\mathrm{VO}_{2}\right)$, carbon dioxide excretion $\left(\mathrm{VCO}_{2}\right)$, and minute pulmonary ventilation (VE). Maximal oxygen uptake $\left(\mathrm{VO}_{2 \max }\right)$ was calculated based on the composition of expired air and minute ventilation. All measures were averaged over 30-s intervals. Maximal oxygen uptake and maximal aerobic power were calculated relative to body mass $\left(\mathrm{VO}_{2 \max }\right.$ and $\mathrm{P}_{\max }$, respeticely) and lean body mass $\left(\mathrm{LBM}-\mathrm{VO}_{2 \max }\right.$ and LBM-P $_{\max }$, respectively).

Achievement of $\mathrm{VO}_{2 \max }$ was verified based on the incidence of the plateau phase in $\mathrm{VO}_{2 \max }$ (Dempsey and Wagner 1999). The plateau response was determined using previously established methods in which $\mathrm{VO}_{2}$ was averaged over 15 -s intervals and designated as the period when $\mathrm{VO}_{2}$ did not fluctuate $\leq 1.5 \mathrm{ml} \cdot \mathrm{kg}^{-1} \cdot \mathrm{min}^{-1}$ from the $\mathrm{VO}_{2 \max }$ (Doherty et al. 2003, Lucia et al. 2006). Plateau $\mathrm{VO}_{2 \max }$ duration was calculated in seconds $\left(\mathrm{T}_{\text {plateau }}\right)$ and is presented in Table 1.

\section{Sprint interval testing protocol}

The SITP was performed on the same Lode Excalibur Sport cycle ergometer. The test was preceded by a warm-up begun at a workload corresponding to 
$40 \%$ Pmax (determined in ITP) for $5 \mathrm{~min}$ and then at $50 \% \mathrm{P}_{\max }$ for $15 \mathrm{~min}$. The participant then performed an active cool-down at $10 \% \mathrm{P}_{\max }$ for $10 \mathrm{~min}$ followed by a 5-min rest. The test proper involved a set of four 30-s maximal cycling sprints with the participant motivated to attain peak power as quickly as possible and maintain maximum cycling cadence. Workload was individually determined at a fixed-mean crank torque of $0.8 \mathrm{~N} \cdot \mathrm{m}$ per $\mathrm{kg}$ of BM. Each repetition was interspersed with 90 seconds of active recovery in which workload was decreased to $30 \mathrm{~W}$. Upon concluding the last repetition, the participant performed an active cool-down at $30 \mathrm{~W}$ for $2 \mathrm{~min}$.

Power output was recorded in each sprint repetition to determine the highest absolute measure of peak power in the set $\left(\mathrm{P}_{\text {peak }}\right)$ and average power for the entire set $\left(\mathrm{P}_{\mathrm{av}}\right)$. Respiratory function was evaluated using the same procedures and equipment as in the ITP with data collected from the beginning of the first sprint until 2 min after set termination. Total oxygen uptake $\left(\mathrm{VO}_{2 \text { tot }}\right)$ was calculated as the sum of oxygen uptake across this interval and peak oxygen uptake $\left(\mathrm{VO}_{2 \text { peak }}\right)$ was determined as the highest absolute measure of $\mathrm{VO}_{2}$
(Hebisz et al. 2017). The power and oxygen measures were then calculated in relation to body mass $\left(\mathrm{P}_{\mathrm{av}}\right.$, $\mathrm{P}_{\text {peak }}, \mathrm{VO}_{2 \text { tot }}, \mathrm{VO}_{2 \text { peak }}$ ) and lean body mass (LBM- $\mathrm{P}_{\mathrm{av}}$,

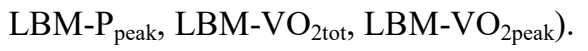

Body surface temperature during the SITP was measured using a Sonel KT384 thermal imaging camera (Sonel S.A., Świdnica, Poland). The camera has a $384 \times 288$ infrared resolution at a spectral range of $8-14 \mu \mathrm{m}$ and thermal sensitivity of $0.08^{\circ} \mathrm{C}$. Data was processed using prepackaged software (Sonel ThermoAnalyzer) to extrapolate skin temperature into ${ }^{\circ} \mathrm{C}$. During playback, single frames were analyzed and the average temperature across 10-pixel square targets on the temple and arm were recorded (Fig. 1). The temple site was chosen due to the superficial network of blood vessels local to the temporal artery (Marano et al. 1985) whereas the forearm measurement site served as a comparative measurement. Temperature was measured while stationary after the warm-up as a baseline immediately prior to SITP $\left(\mathrm{T}_{\mathrm{b}}\right)$, immediately after the first sprint $\left(\mathrm{T}_{1}\right), 80$ seconds after the first sprint $\left(\mathrm{T}_{2}\right)$, immediately after the fourth sprint $\left(\mathrm{T}_{3}\right)$, and 80 seconds after the fourth sprint $\left(\mathrm{T}_{4}\right)$.

Table 2. Temple and arm temperature in subsequent measurements during sprint interval testing protocol.

\begin{tabular}{|c|c|c|c|c|c|}
\hline & $\mathbf{T}_{\mathrm{b}}\left[{ }^{\circ} \mathbf{C}\right]$ & $\mathrm{T}_{1}\left[{ }^{\circ} \mathrm{C}\right]$ & $\mathbf{T}_{2}\left[{ }^{\circ} \mathbf{C}\right]$ & $\mathbf{T}_{3}\left[{ }^{\circ} \mathbf{C}\right]$ & $\mathbf{T}_{4}\left[{ }^{\circ} \mathbf{C}\right]$ \\
\hline Temple & $30.9(2.8)$ & $30.3(2.9)$ & $30.1(2.7)$ & $31.2(3.1)$ & $32.1(2.9)^{* \mathrm{~T} 2}$ \\
\hline Arm & $29.4(3.5)$ & $29.7(3.6)$ & $30(3.8)$ & $30.9(4.5)$ & $31.5(4.4)$ \\
\hline
\end{tabular}

$T_{b}$ - the baseline temperature of the body surface, $T_{1}$ - body surface temperature immediately after the first sprint; $T_{2}$ - body surface temperature 80 seconds after the first sprint; $\mathrm{T}_{3}$ - body surface temperature immediately after the fourth sprint; $\mathrm{T}_{4}$ - body surface temperature 80 seconds after the fourth sprint; ${ }^{* T 2}-P<0.05$ significant difference between $\mathrm{T}_{4}$ Vs. $\mathrm{T}_{2} ;$ data are presented as arithmetic mean (standard deviation)

Table 3. Power output and oxygen uptake values.

\begin{tabular}{|c|c|c|c|}
\hline Incremental testing protocol & & Sprint interval testing protocol & \\
\hline$P_{\max }\left[W \cdot \mathrm{kg}^{-1}\right]$ & $5.6(0.3)$ & $P_{\text {peak }}\left[W \cdot \mathrm{kg}^{-1}\right]$ & $19.9(3.0)$ \\
\hline$L B M-P_{\max }\left[W \cdot \mathrm{kg}^{-1}\right]$ & $6.6(0.5)$ & $L B M-P_{\text {peak }}\left[W \cdot \mathrm{kg}^{-1}\right]$ & $23.1(3.4)$ \\
\hline$V O_{2 \max }\left[\mathrm{ml} \cdot \mathrm{min}^{-1} \cdot \mathrm{kg}^{-1}\right]$ & $66.3(4.6)$ & $P_{a v}\left[W \cdot \mathrm{kg}^{-1}\right]$ & $9.4(0.5)$ \\
\hline \multirow[t]{5}{*}{$L B M-V O_{2 \max }\left[\mathrm{ml} \cdot \mathrm{min}^{-1} \cdot \mathrm{kg}^{-1}\right]$} & $76.6(5.5)$ & $L B M-P_{a v}\left[W \cdot \mathrm{kg}^{-1}\right]$ & $10.9(0.7)$ \\
\hline & & $\mathrm{VO}_{2 \text { peak }}\left[\mathrm{ml} \cdot \mathrm{min}^{-1} \cdot \mathrm{kg}^{-1}\right]$ & $53.3(4.1)$ \\
\hline & & $L B M-V O_{2 p e a k}\left[\mathrm{ml} \cdot \mathrm{min}^{-1} \cdot \mathrm{kg}^{-1}\right]$ & $69.0(7.0)$ \\
\hline & & $V O_{2 t o t}\left[\mathrm{ml} \cdot \mathrm{kg}^{-1}\right]$ & $315.6(20.8)$ \\
\hline & & $L B M-V O_{2 t o t}\left[\mathrm{ml} \cdot \mathrm{kg}^{-1}\right]$ & $366(33.5)$ \\
\hline
\end{tabular}

\footnotetext{
$\mathrm{P}_{\max }$ - maximal aerobic power; $\mathrm{VO}_{2 \max }$ - maximal oxygen uptake; $\mathrm{P}_{\text {peak }}$ - peak power; $\mathrm{P}_{\mathrm{av}}$ - average power; $\mathrm{VO}_{2 \text { peak }}$ - peak oxygen uptake;
} $\mathrm{VO}_{2 \text { tot }}$ - sum of total oxygen uptake; LBM - relative to lean body mass; data are presented as arithmetic mean (standard deviation) 
The measurement of temperature during actual sprint execution was not possible as the participants stood on the pedals and introduced significant motion blur. The delta difference between the temperature measures and baselines was then calculated separately for the temple $\left(\Delta \mathrm{Tt}_{1}, \Delta \mathrm{Tt}_{2}, \Delta \mathrm{Tt}_{3}, \Delta \mathrm{Tt}_{4}\right)$ and $\operatorname{arm}\left(\Delta \mathrm{Ta}_{1} \Delta \mathrm{Ta}_{2}, \Delta \mathrm{Ta}_{3}, \Delta \mathrm{Ta}_{4}\right)$.

\section{Statistical analysis}

Data were processed using the Statistica 13.1 software package (Statsoft, USA). The distribution of the data set was checked using the Shapiro-Wilk test with normal distributions found for all measures except $\Delta \mathrm{Ta}_{2}$. Means and standard deviations were calculated and one-

Table 4. Correlations between selected power output and oxygen uptake variables and the difference in temple surface temperature measured during sprint interval testing protocol.
$\Delta \mathrm{Tt}_{1}\left[{ }^{\circ} \mathrm{C}\right]$
$\Delta \mathrm{Tt}_{2}\left[{ }^{\circ} \mathrm{C}\right]$
$\Delta \mathrm{Tt}_{3}\left[{ }^{\circ} \mathrm{C}\right]$
$\left.\Delta \mathrm{Tt}_{4}{ }{ }^{\circ} \mathrm{C}\right]$

\section{Incremental testing protocol}

$\begin{array}{lcccc}P_{\max }\left[W \cdot \mathrm{kg}^{-1}\right] & 0.13 & 0.16 & 0.41 & 0.47^{*} \\ L B M-P_{\max }\left[\mathrm{W} \cdot \mathrm{kg}^{-1}\right] & 0.16 & 0.39 & 0.55^{*} & 0.63^{*} \\ V O_{2 \max }\left[\mathrm{ml} \cdot \mathrm{min}^{-1} \cdot \mathrm{kg}^{-1}\right] & 0.27 & 0.28 & 0.47^{*} & 0.52^{*} \\ L B M-V O_{2 \max }\left[\mathrm{ml}^{-1} \mathrm{~min}^{-1} \cdot \mathrm{kg}^{-1}\right] & 0.4 & 0.54^{*} & 0.72^{*} & 0.75^{*}\end{array}$

\section{Sprint interval testing protocol}

$\begin{array}{lcccc}P_{\text {peak }}\left[W \cdot \mathrm{kg}^{-1}\right] & -0.16 & -0.15 & -0.28 & -0.28 \\ L B M-P_{\text {peak }}\left[W \cdot \mathrm{kg}^{-1}\right] & -0.07 & 0.00 & -0.09 & -0.1 \\ P_{a v}\left[W \cdot \mathrm{kg}^{-1}\right] & -0.24 & -0.15 & -0.03 & -0.06 \\ L B M-P_{a v}\left[W \cdot \mathrm{kg}^{-1}\right] & 0.07 & 0.19 & 0.43 & 0.37 \\ V O_{2 p e a k}\left[\mathrm{ml} \cdot \mathrm{min}^{-1} \cdot \mathrm{kg}^{-1}\right] & -0.08 & -0.04 & 0.56^{*} & 0.51^{*} \\ L B M-V O_{2 p e a k}\left[\mathrm{ml} \cdot \mathrm{min}^{-1} \cdot \mathrm{kg}^{-1}\right] & 0.08 & 0.17 & 0.66^{*} & 0.61^{*} \\ V O_{2 t o t}\left[\mathrm{ml} \cdot \mathrm{kg}^{-1}\right] & -0.23 & -0.18 & 0.34 & 0.26 \\ L B M-V O_{2 t o t}\left[\mathrm{ml} \cdot \mathrm{kg}^{-1}\right] & 0.00 & 0.1 & 0.52^{*} & 0.45^{*}\end{array}$

$\Delta \mathrm{Tt}_{1}$ - difference between the temple temperature measured immediately after the first sprint and the baseline temperature, $\Delta \mathrm{Tt}_{2}-$ difference between the temple temperature measured 80 seconds after the first sprint and the baseline temperature; $\Delta \mathrm{Tt}_{3}-$ difference between the temple temperature measured immediately after the fourth sprint and the baseline temperature; $\Delta \mathrm{Tt}_{4}$ - difference between the temple temperature measured 80 seconds after the fourth sprint and the baseline temperature; LBM - parameter converted into lean body mass; $\mathrm{P}_{\max }$ - maximal aerobic power; $\mathrm{VO}_{2 \max }$ - maximal oxygen uptake; $\mathrm{P}_{\text {peak }}$ - peak power; $\mathrm{P}_{\mathrm{av}}$ - average power; $\mathrm{VO}_{2 \text { peak }}-$ peak oxygen uptake; $\mathrm{VO}_{2 \text { tot }}$ - the sum of oxygen uptake; ${ }^{*}-P<0.05$
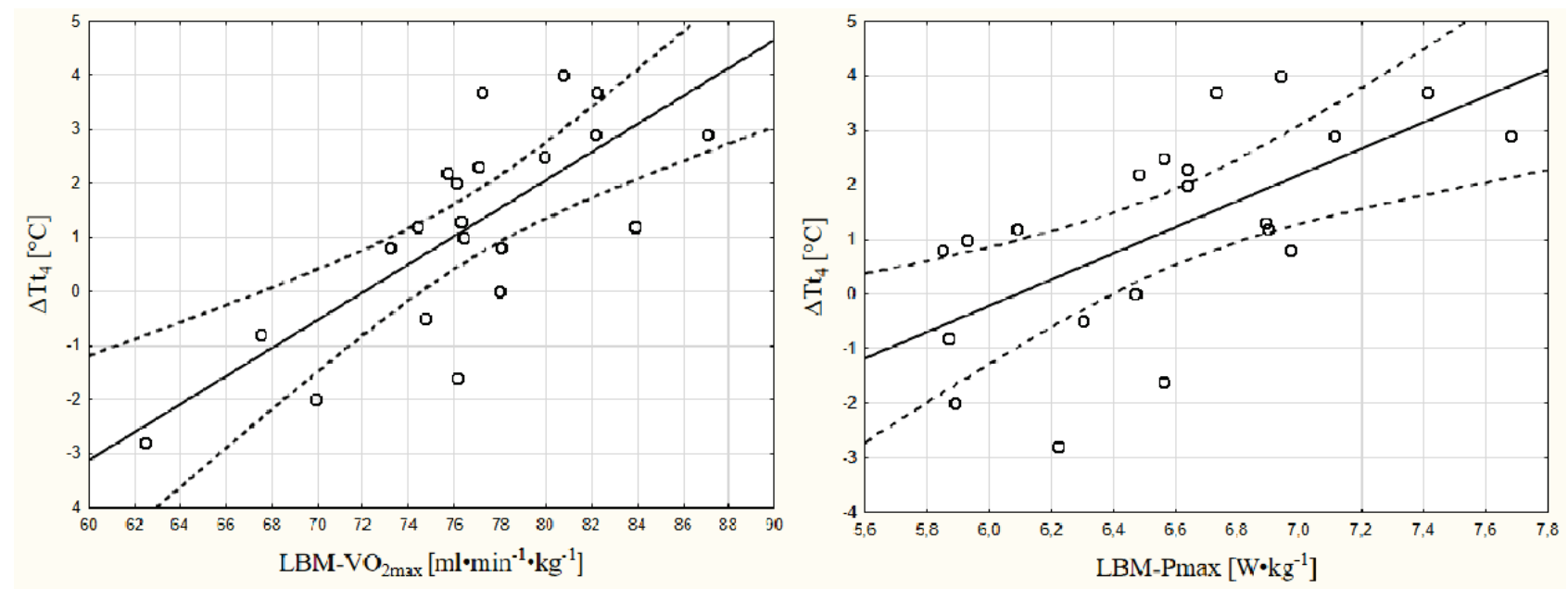

Fig. 2. Plots showing the correlation between aerobic capacity, after taking the lean body mass into account, and the change in the temple surface temperature 80 seconds after the fourth sprint in relation to the baseline temperature. The aerobic capacity is represented by maximal oxygen uptake (left plot) and maximal aerobic power (right plot). 
way analysis of variance with the Duncan test administered post hoc was used to compare the differences for statistical significance. Pearson's correlation coefficients were calculated between the power and oxygen uptake measures in the ITP and SITP and $\Delta \mathrm{Tt}_{1}, \Delta \mathrm{Ta}_{1}, \Delta \mathrm{Tt}_{2}, \Delta \mathrm{Ta}_{2}, \Delta \mathrm{Tt}_{3}, \Delta \mathrm{Ta}_{3}, \Delta \mathrm{Tt}_{4}$, and $\Delta \mathrm{Ta}_{4}$. Linear regression analyses were performed for the variables that showed the strongest correlations. The significance level for all statistical procedures was set at $p<0.05$.

\section{Results}

Temple temperature significantly increased 80 seconds after the fourth sprint $\left(\mathrm{Tt}_{4}\right)$ in comparison with temperature 80 seconds after the first sprint $\left(\mathrm{Tt}_{2}\right)$. There were no significant changes in arm temperature (Table 2). The values of power output and oxygen uptake in the ITP and SITP as absolute measures and relative to lean body mass are presented in Table 3 . The difference between the temple temperature measured 80 seconds after the first sprint and baseline $\left(\Delta \mathrm{Tt}_{2}\right)$ correlated positively only with relative maximal oxygen uptake measured in the ITP $\left(\mathrm{LBM}-\mathrm{VO}_{2 \max }\right)$. The differences between temple temperature measured immediately after the fourth sprint $\left(\Delta \mathrm{Tt}_{3}\right)$ and 80 seconds after the fourth sprint $\left(\Delta \mathrm{Tt}_{4}\right)$ and baseline correlated positively with $\mathrm{P}_{\max }$, LBM- $\mathrm{P}_{\max }, \mathrm{VO}_{2 \max }$ and $\mathrm{LBM}-\mathrm{VO}_{2 \max }$ obtained in ITP

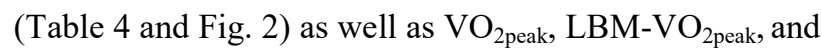
LBM- $\mathrm{VO}_{2 \text { tot }}$ obtained in the SITP (Table 4). Regression equations were determined for $\mathrm{LBM}-\mathrm{P}_{\max }\left(\mathrm{LBM}-\mathrm{P}_{\max }=\right.$ $\left.6.38+0.17 \cdot \Delta \mathrm{Tt}_{4}\right), \mathrm{LBM}-\mathrm{VO}_{2 \max }\left(\mathrm{LBM}-\mathrm{VO}_{2 \max }=74.08+\right.$ $\left.2.15 \cdot \Delta \mathrm{Tt}_{4}\right)$, and $\mathrm{LBM}-\mathrm{VO}_{2 \text { peak }}\left(\mathrm{LBM}-\mathrm{VO}_{2 \text { peak }}=68.46+\right.$ $\left.2.52 \cdot \Delta \mathrm{Tt}_{3}\right)$. There were no statistically significant correlations between the arm temperature changes and oxygen uptake and power variables in either the ITP or SITP.

\section{Discussion}

The results obtained in the present study did not show any significant correlations between the delta change in body surface temperature measured immediately after the first sprint compared with baseline $\left(\Delta \mathrm{Tt}_{1}\right)$ were found with any of the measures of aerobic capacity. The lack of a correlation may be related to the relatively low stroke volume induced at this phase of the SITP due to delayed cardiac output kinetics in response to high-intensity exercise (Davies et al. 1972, Zakynthinaki
2015). In addition, this finding may also be explained by the delayed increase in cutaneous blood circulation at the onset of exercise (Johnson 1992, Simmons et al. 2011). The growing demand for oxygen by exercising skeletal muscle at the beginning of such high-intensity efforts induces the secretion of norepinephrine stimulating the post-synaptic receptors alpha $a_{1}$ and alpha $_{2}$ to cause strong vasoconstriction of the cutaneous blood vessels (Johnson 1992, Johnson 1998).

Further comparisons in temple temperature showed significant correlations with both the ITPobtained measures of aerobic capacity and SITP-based aerobic metabolism. Particularly strong correlations were obtained when comparing the delta temperatures with $\mathrm{VO}_{2 \max }$ relative to lean body mass $\left(\mathrm{LBM}-\mathrm{VO}_{2 \max }\right)$, which may be explained by the propensity of individuals with high aerobic capacity to show enhanced metabolic function and thermoregulatory adaptations. Thermal output by contracting skeletal muscle is dependent on the metabolic response to exercise and the involvement of the aerobic and anaerobic energy pathways (GonzalezAlonso 2012). Sprint interval training is a particularly high energy demanding activity that severely taxes both pathways as evidenced by high levels of oxygen uptake and post-exercise lactate concentrations (Buchheit et al. 2012, Hebisz et al. 2017). The dissipation of heat generated by such intensive exercise is then modulated by several physiological mechanisms including stroke volume (Johnson 1998), blood volume (Morimoto 1990, Warburton et al. 1999), and the convective transport of heat via blood flow (Gonzalez-Alonso 2012). The above mechanisms are also strongly interrelated with $\mathrm{VO}_{2 \max }$ (Gledhill et al. 1992, Martino et al. 2002, Mujika and Padilla 2001b, Mujika and Padilla 2000, O’Neill et al. 2016), which further explains the correlations that were observed with post-exercise changes in temple surface temperature. The present results are also in concurrence with the literature on the high level of cutaneous blood flow during exercise in trained individuals (Fritzsche and Coyle 2000, Johnson 1998, Tankersley et al. 1991) and higher rectal temperature of individuals with high $\mathrm{VO}_{2 \max }$ during exercise in a warm environment (Mora-Rodriguez 2010).

The strongest correlation was observed between the delta change in temple temperature and $\mathrm{VO}_{2 \max }$ relative to lean body mass $\left(\mathrm{LBM}-\mathrm{VO}_{2 \max }\right)$. This may be explained by the significant redistribution of blood flow in response to the heat generated by working skeletal muscle (Johnson 1992). This results in a significant 
increase in external carotid artery blood flow with a concomitant decrease in internal carotid artery and vertebral artery blood flow (Ogoh et al. 2013). Wilson et al. (2006) observed markedly increased cerebral vascular resistance and reduced blood velocity in response to thermal stress. As a result, blood distribution is modified with increased extracranial blood supply to enhance the dissipation of heat via cutaneous circulation (Ogoh et al. 2013). The above adaptations are observed with a concurrent reduction in cutaneous vascular resistance due to the decrease in adrenergic innervation and, as exercise continues, increased non-adrenergic vasodilatation (Hogan 2009, Johnson 1998). Johnson (1998) had previously suggested that cutaneous blood circulation is regulated by an internal temperature threshold that modulates blood flow and the body's sensitivity to internal temperature changes particularly when exercise is performed. These mechanisms best explain the increase in temple surface temperature postSITP in comparison with the temperature after the first sprint and the strong correlation that was observed between $\mathrm{VO}_{2 \max }$ and the changes in the temperature upon concluding the SITP. This finding suggests that $\mathrm{VO}_{2 \max }$ may be predicted via changes in temple temperature during maximal sprint exercise as the higher the maximal oxygen uptake, the greater increase in skin surface temperature in order to enhance heat dissipation during exercise.

A strong correlation was also found between the delta change in temple temperature and $\mathrm{VO}_{2 \text { peak }}$ relative to lean body mass $\left(\mathrm{LBM}-\mathrm{VO}_{2 \text { peak }}\right)$. This result suggests that temple temperature can also serve as an indicator of aerobic metabolic rate during repeated sprint exercise. However, in contrast to the results of the ITP, no statistically significant relationship was observed between the delta change in temple temperature and $\mathrm{P}_{\text {peak }}$ or $\mathrm{P}_{\mathrm{av}}$ in the SITP. The lack of any correlation may reside in the fact that repeated sprinting performance is determined to a larger extent by the anaerobic metabolism of phosphocreatine and glucose and the accumulation of metabolites in muscles than an incremental exercise test (Girard et al. 2011). Therefore, it appears that the role of cardiovascular fitness in the delivery of oxygen to working muscle during repeated sprint exercise is less important than when performing incremental exercise (Buchheit et al. 2012, Girard et al. 2011, Hebisz et al. 2017).

Based on the present results, it can be concluded that body surface temperature during and after a single bout of sprint interval exercise can serve as an indirect method for predicting aerobic capacity, as higher $\mathrm{VO}_{2 \max }$ is associated with a greater increase in temple surface temperature during such intensive exercise. Presently, the strongest correlations were observed between $\mathrm{VO}_{2 \max }$ and the delta change in temple temperature immediately and 80 seconds after the fourth (and last) sprint repetition when compared with baseline values. Future research is needed to confirm the changes in body surface temperature in a wider range of measurement sites during and after additional exercise modalities in populations differentiated by $\mathrm{VO}_{2 \max }$, age, and physical activity level.

\section{Conflict of Interest}

There is no conflict of interest.

\section{Acknowledgements}

This work was supported by the Ministry of Science and Higher Education under grant number NRSA300253 titled "Development of Academic Sport". The authors wish to thank Michael Antkowiak for his translation and assistance in preparation of this manuscript.

\section{References}

ABDERRAHMAN AB, PRIOUX J, CHAMARI K, OUNIS OB, TABKA Z, ZOUHAL H: Running interval training and estimated plasma-volume variation. Int J Sports Physiol Perform 8: 358-365, 2013.

BUCHHEIT M, ABBISS CR, PEIFFER JJ, LAURSEN PB: Performance and physiological responses during a sprint interval training session: relationships with muscle oxygenation and pulmonary oxygen uptake kinetics. Eur $J$ Appl Physiol 112: 767-779, 2012.

COLES MG, LUETKEMEIER MJ: Sodium-facilitated hypervolemia, endurance performance and thermoregulation. Int J Sports Med 26: 182-187, 2005.

COQUART JB, GARCIN M, PARFITT G, TOURNY-CHOLLET C, ESTON RG: Prediction of maximal or peak oxygen uptake from ratings of perceived exertion. Sports Med 44: 563-578, 2014. 
DAVIES CTM, DI PRAMPERO PE, CERRETELLI P: Kinetics of cardiac output and respiratory gas exchange during exercise and recovery. J Appl Physiol 32: 618-625, 1972.

De LORENZO A, DA SILVA CL, CASTRO SOUZA FC, DE SOUZA LEÃO LIMA R: Value of the oxygen pulse curve for the diagnosis of coronary artery disease. Physiol Res 67: 679-686, 2018.

DEMPSEY JA, WAGNER PD: Exercise-induced arterial hypoxemia. J Appl Physiol 87: 1997-2006, 1999.

DOHERTY M, NOBBS L, NOAKES T: Low frequency of the "plateau phenomenon" during maximal exercise in elite British athletes. Eur J Appl Physiol 89: 619-623, 2003.

FARIA EW, PARKER DL, FARIA IE: The science of cycling: physiology and training - part 1. Sports Med 35: 285-312, 2005.

FRITZSCHE RG, COYLE EF: Cutaneous blood flow during exercise is higher in endurance-trained humans. $J$ Appl Physiol 88: 738-744, 2000.

GIRARD O, MENDEZ-VILLANUEVA A, BISHOP D: Repeated-sprint ability - Part I. Factors contributing to fatigue. Sports Med 41: 673-694, 2011.

GLAISTER M: Multiple sprint work. Physiological responses, mechanisms of fatigue, and the influence of aerobic fitness. Sports Med 35: 757-777, 2005.

GLEDHILL N, WARBURTON D, JAMNIK V: Hemoglobin, blood volume, cardiac function, and aerobic power. Can J Appl Physiol 24: 54-65, 1992.

GONZALEZ-ALONSO J: Human thermoregulation and the cardiovascular system. Exp Physiol 97: 340-346, 2012.

HEBISZ R, HEBISZ P, ZATOŃ M, MICHALIK K: Peak oxygen uptake in a sprint interval testing protocol vs. maximal oxygen uptake in an incremental testing protocol and their relationship with cross-country mountain biking performance. Appl Physiol Nutr Metab 42: 371-376, 2017.

HOGAN TS: Exercise-induced reduction in systemic vascular resistance: a covert killer and an unrecognised resuscitation challenge? Med Hypotheses 73: 479-484, 2009.

JOHNSON JM: Exercise and the cutaneous circulation. Exerc Sport Sci Rev 20: 59-97, 1992.

JOHNSON JM: Physical training and the control of skin blood flow. Med Sci Sports Exerc 30: 382-386, 1998.

JOHNSON JM, ROWELL LB: Forearm skin and muscle vascular responses to prolonged leg exercise in man. J Appl Physiol 39: 920-924, 1975.

KAMON E, BELDING HS: Dermal blood flow in the resting arm during prolonged leg exercise. $J$ Appl Physiol 26: 317-320, 1969.

KENNEY WL, JOHNSON JM: Control of skin blood flow during exercise. Med Sci Sports Exerc 24: 303-312, 1992.

LEVINE BD: $\mathrm{VO}_{2}$ max: what do we know, and what do we still need to know? J Physiol 586: 25-34, 2008.

LOPES AJ, VIGÁRIO PS, HORA AL, DEUS CAL, SOARES MS, GUIMARÃES FS, FERREIRA AS: Ventilation distribution, pulmonary diffusion and peripheral muscle endurance as determinants of exercise intolerance in elderly patients with chronic obstructive pulmonary disease. Physiol Res 67: 863-874, 2018.

LORENZO S, HALLIWILL JR, SAWKA MN, MINSON CT: Heat acclimation improves exercise performance. J Appl Physiol 109: 1140-1147, 2010.

LUCIA A, HOYOS J, CHICHARRO JL: Physiology of professional road cycling. Sports Med 31: 325-337, 2001.

LUCIA A, RABADAN M, HOYOS J, HERNANDEZ-CAPILLA M, PEREZ M, SAN JAUN AF, EARNEST CF, CHICHARRO JL: Frequency of the VO2max plateau phenomenon in world class cyclists. Int J Sports Med 27: 984-992, 2006.

MARANO SR, FISCHER DW, GAINES C, SONNTAG VK: Anatomical study of the superficial temporal artery. Neurosurgery 16: 786-790, 1985.

MARTINO M, GLEDHILL N, JAMNIK V: High VO2max with no history of training is primarily due to high blood volume. Med Sci Sports Exerc 34: 966-971, 2002.

MORA-RODRIGUEZ R, DEL COSO J, HAMOUTI N, ESTEVEZ E, ORTEGA JF: Aerobically trained individuals have greater increases in rectal temperature than untrained ones during exercise in the heat at similar relative intensities. Eur J Appl Physiol 109: 973-981, 2010.

MORIMOTO T: Thermoregulation and body fluids: role of blood volume and central venous pressure. Jpn J Physiol 40: 165-179, 1990. 
MUJIKA I, PADILLA S: Detraining: loss of training-induced physiological and performance adaptations. Part I: short term insufficient training stimulus. Sports Med 30: 79-87, 2000.

MUJIKA I, PADILLA S: Physiological and performance characteristics of male professional road cyclists. Sports Med 31: 479-487, 2001a.

MUJIKA I, PADILLA S: Muscular characteristics of detraining in humans. Med Sci Sports Exerc 33: 1297-1303, $2001 b$.

NELSON MD, STUART-HILL LA, SLEIVERT GG: Hypervolemia and blood alkalinity: effect on physiological strain in a warm environment. Int $J$ Sports Physiol Perfor 3: 501-515, 2008.

NYBO L, NIELSEN B: Hyperthermia and central fatigue during prolonged exercise in humans. $J$ Appl Physiol 91: 1055-1060, 2001.

OGOH S, SATO K, OKAZAKI K, MIYAMOTO T, HIRASAWA A, MORIMOTO K, SHIBASAKI M: Blood flow distribution during heat stress: cerebral and systemic blood flow. J Cereb Blood Flow Metab 33: 1915-1920, 2013.

O'NEILL CD, KIMMERLY DS, DOGRA S: Central and peripheral response to incremental cycling exercise in older untrained active men: A comparison of those in-between. Physiol Res 65: 303-309, 2016.

RACINAIS S, MOUSSAY S, NICHOLS D, TRAVERS G, BELFEKIH T, SCHUMACHER YO, PERIARD JD: Core temperature up to $41.5^{\circ} \mathrm{C}$ during the UCI Road Cycling World Championships in the heat. Br J Sports Med 53: 426-429, 2019.

SIMMONS GH, PADILLA J, YOUNG CN, WONG BJ, LANG JA, DAVIS MJ, LAUGHLIN MH, FADEL PJ: Increased brachial artery retrograde shear rate at exercise onset is abolished during prolonged cycling: role of thermoregulatory vasodilation. J Appl Physiol 110: 389-397, 2011.

TANKERSLEY CG, SMOLANDER J, KENNEY WL, FORTNEY SM: Sweating and skin blood flow during exercise: effects of age and maximal oxygen uptake. J Appl Physiol 71: 236-242, 1991.

TAYLOR WF, JOHNSON JM, KOSIBA WA: Roles of absolute and relative load in skin vasoconstrictor responses to exercise. J Appl Physiol 69: 1131-1136, 1990.

VIGELSØ A, PRATS C, PLOUG T, DELA F, HELGE JW: Higher muscle content of perilipin 5 and endothelial lipase protein in trained than untrained middle-aged men. Physiol Res 65: 293-302, 2016.

WARBURTON DE, GLEDHILL N, JAMNIK VK, KRIP B, CARD N: Induced hypervolemia, cardiac function, VO2max, and performance of elite cyclists. Med Sci Sports Exerc 31: 800-808, 1999.

WARBURTON DE, HAYKOWSKY MJ, QUINNEY HA, BLACKMORE D, TEO KK, TAYLOR DA: Blood volume expansion and cardiorespiratory function: effects of training modality. Med Sci Sport Exerc 36: 991-1000, 2004.

WILSON TE, CUI J, ZHANG R, CRANDALL CG: Heat stress reduces cerebral blood velocity and markedly impairs orthostatic tolerance in humans. Am J Physiol Regul Integr Comp Physiol 291: 1443-1448, 2006.

WINGO JE, LOW DA, KELLER DM, BROTHERS RM, SHIBASAKI M, CRANDALL CG: Skin blood flow and local temperature independently modify sweat rate during passive heat stress in humans. J Appl Physiol 109: 1301-1306, 2010.

YOSHIDA T, NAGASHIMA K, NOSE H, KAWABATA T, NAKAI S, YORIMOTO A, MORIMOTO T: Relationship between aerobic power, blood volume, and thermoregulatory responses to exercise-heat stress. Med Sci Sports Exerc 29: 867-873, 1997.

ZAKYNTHINAKI MS: Modelling heart rate kinetics. PLoS One 10: 1-26, 2015. 